\title{
Electrocardiogram Derived Flag
}

National Cancer Institute

\section{Source}

National Cancer Institute. Electrocardiogram Derived Flag. NCI Thesaurus. Code C83255.

An indication or description that electrocardiog ram data is a derived value. 